\title{
Whistleblowing in Healthcare for Patient Safety: An Integrative Literature Review
}

\author{
Lyndon Garvin Augustine, Ph.D. \\ School of Business Analytics and Decision Sciences, Capitol Technology University \\ 11301 Springfield Rd, Laurel, MD 20708, United States
}

Received: Dec. 7, 2021 Accepted: Jan. 6, 2022 Online published: Jan. 19, 2022

doi:10.5296/ijhrs.v12i1.19477ＵRL: https://doi.org/10.5296/ijhrs.v12i1.19477

\begin{abstract}
Patient safety has progressed over the past decade from being a relatively insignificant issue to a position of high importance for healthcare executives and policy makers. However, most of the opportunities for healthcare professionals to identify and act upon patient safety concerns are likely to occur much further upstream, such as, within the day-to-day mundane activities. Because of this, policy makers have ramped up the focus on the role of "whistleblowers" towards raising concerns around patient safety in healthcare settings. The notion of whistleblowing in healthcare has been known to bring healthcare scandals to light, which in essence has contributed to preventing future harm to patients. Although this may be true, when compared to other industries, there remains relatively little research on whistleblowing in healthcare. For this reason, the purpose of this study was to examine the role of organizational culture and change in healthcare, the link between ethics and whistleblowing, and the processes and levels of whistleblowing within healthcare. By focusing on these, the researcher was successful in highlighting a series of organizational factors that has been known to both inhibit and foster whistleblowing within healthcare. Thereafter, the researcher then suggested steps that can be used to help organizations build and sustain an ethical culture where whistleblowing is viewed as a morale right.
\end{abstract}

Keywords: Whistleblower, Organizational Culture, Patient Safety, Healthcare Whistleblowing, Ethics

\section{Introduction}

To blow or not to blow the whistle? A hamletic doubt in health care. The dilemma about to blow or not blow the whistle when a misconduct occurs in health care is very common and challenging (MacDougall, 2016). The reason for this dilemma stems from the fact that the policies around whistleblowing are strongly linked to how well organizations provides its 
services to help keep patients safe (Ciasullo et al., 2017). As defined by Skagerström et al. (2017), patient safety is the: "protection against adverse events" where adverse events are defined as "suffering bodily or mental harm or illness and deaths that could have been avoided if adequate measures had been taken at the patient contact with the healthcare system" (p. 232).

Using this definition as a guide in healthcare organizations, employees should be alarmed with the processes used to drive patient safety initiatives that could be championed through whistleblowing practice. Because of this, whistleblowing could be looked upon as an ethical duty instead of an action to a precise code of ethics (Ciasullo et al., 2017). Conversely, keeping patients safe and being an advocate for this practice should be viewed as a principal component to inspire healthcare professional to blow the whistle, with the intention of safeguarding patients and enhancing the quality of care as the central theme (Johnstone, 2009).

With that said, the purpose of this literature review was to examine the role of organizational culture and change in healthcare, the link between ethics and whistleblowing, and the processes and levels of whistleblowing within healthcare. Additionally, the goal of this research was to explore the organizational factors that can both inhibit and foster whistleblowing within healthcare. What's more, the significance of this research was that it provided a different perspective on the already existing problem in healthcare as it relates to healthcare organizations not creating an environment that advocates whistle-blowing as an expectation.

Through existing scholarly literature, the researcher added depth and situational awareness to the impact of ethics, organizational culture, and leaderships' ability to influence healthcare workers to create and maintain a safe environment for patients. Finally, from an academic contribution, this research may benefit patients to help improve the quality of services they receive throughout the continuum of their care, it may benefit healthcare workers to help them find their voice to speak up for patient safety, it may benefit healthcare leaders to identify any gaps between existing practices being used versus best practices as it relates to building and sustaining an ethical culture towards advocating whistle-blowing in healthcare, and it may benefit future scholars who want to build on this research topic.

\section{Literature Review}

\subsection{Organizational culture and change}

Organizational culture is normally viewed as the heartbeat of an organization. As presented by Evans et al. (2015), expansive altering in healthcare often seeks to achieve visionary accomplishment advancement via foundational movements in the types of care that is offered, the way the care is carried out, and/or the shape and processes deciding the distribution of care. However, executing and undergoing sweeping change in healthcare organizations and networks is a laborious and often evasive task. In spite of the use of verification and best practices, end results linked with wide change efforts are often temporary, unsteady or frivolous (Evans et al., 2015, p. 874). 


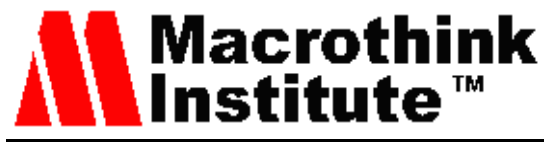

International Journal of Human Resource Studies

ISSN 2162-3058

2022, Vol. 12, No. 1

Evans further argued that expansive change in healthcare inescapably involves the consultation of a host of multiple players from organizations across the spectrum of care. To illustrate, Evans suggested that expansive change could not be realized without collaboration, inter-departmental, and cross-sectional collaboration because execution of new plans, technologies, and relationships impede existing assumptions and customs and often produce obscurity, unreliability, and logical chaos among leadership (Evans et al., 2015, p. 875).

This view was also supported by Longenecker et al. (2014) who concluded that a key set of components need to be in place for an organization to implement successful change and improvement on an ongoing basis. Longenecker implied that healthcare leaders must foster an organizational culture that embraces and enacts these critical fundamental practices with passion and acumen, and when organizational leaders do not create such a culture, change and improvement efforts are problematic (p.148). With this in mind, Longenecker cited that ineffective leadership and lack of trust in upper management is a barrier towards fostering an organizational culture that embraces successful change and improvement on an ongoing basis (p. 151).

Although there has been many overlapping and competing definitions of organizational culture, many believe that there are various levels to this system. Evans et al. (2015) believed that the term is used fundamentally to refer to the beliefs and behavior patterns dominant among a group of people. Hence, Evans et al. (2015) viewed culture as the "social glue" binding an organization (or parts of an organization) together (p. 876). Evans further stated that organizational culture displays at various levels, on a spectrum from the accepted and unwitnessed to the more apparent and conspicuous.

These proportionally consist of implied, basic beliefs about the world; benefits, faith, and statute of behavior that form organizational objectives and human exchange; obvious remains such as signs, narratives, and formalities; and finally, the explicit behaviors of members of the culture (p. 876). In comparison, Applebaum et al. (2015) described organizational culture as a set of benefits, faith, and behavior designs devising the identification of an organization, and sculpturing employees' behaviors. Suwaryo et al. (2016) stated that organizational culture is a system that involves common actions, values and beliefs developed in the organization and become guidance for its member's behavior.

Suwaryo believed that to understand the importance of organizational culture, it is necessary to discover the culture developed within an organization and what culture the organization members' desire in efforts (p. 69). Despite the various views and definitions surrounding organizational culture and change, one can conclude that the common thread between each is that it all starts with leadership to drive the beliefs and values around this system towards achieving organizational goals.

\subsection{Background on Whistleblowing}

As Bowman (1980) argued, the whistleblowing period began in the latter part of the 1960s as a formation of disagreement to organizational wrong doing. In particular, whistleblowing was seen as an aim to dare unfair administrative actions, for the sake of strengthening 
organizational ability to reach external stakeholders' predictions, and raise quality (Ting, 2008). Nevertheless, in recent years, Holt (2015) cited that whistleblowing has gradually become a mainstream issue in the health care service system where it is discussed as a key tool to merge patient safety and organizational quality.

According to Durante and Gökçe (2017), whistleblowing is described as 'the disclosure by organization members of illegal, immoral, or illegitimate practices under the control of their employers, to persons or organizations that may be able to effect action'. A whistleblower releases information deliberately and employs unconventional methods to make the disclosure (p. 1047). As a comparison, Moore and McAuliffe (2010) defined a whistleblower as "someone who identifies an incompetent, unethical or illegal situation in the workplace and reports it to someone who has the power to stop the wrong (p. 166).

From another perspective, Mannion and Davies (2015) viewed whistleblowing as a procedure that heeds former unofficial attempts to expose wrongdoings and to look into if what is happening in the organization is really wrong. As such, whistleblowing can be viewed as an exertion that makes employees able to give rise to organizational honesty, ethics, and standard, preparing the way for the establishment of social justice (Berry, 2004).

The central theme for each description above is that when normal disclosure channels have failed, a whistleblower may feel compelled to act. When this occurs, Durante and Gökçe (2017) purported that a whistleblower has two dilemmas; a dissent between personal and organizational values, and a dissent between engagements owed to his/her organization and to parties beyond it. Thus, Durante and Gökçe concluded that moral courage and moral reasoning are two of the most important factors to understanding one's propensity to blow the whistle (p. 1047).

\subsection{Healthcare Whistleblowing}

Whistle-blowing has been acknowledge as a prime way of preserving patient safety (Myers, 2008). It is a crucial clinical instrument as needful actions because healthcare institutions are often revealed by whistle-blowers rather than through formal license processes (Taylor, 2010). In few organizations, whistle-blowing is perceived to be the only way mistakes are being discovered and communicated (Blesch, 2010). While nurses account for most whistle-blowers in healthcare settings, physicians, allied health professionals, and even clinical researchers are well-known to hoist the distress in the name of patient safety.

By focusing on situations where the issues relate primarily to the delivery of healthcare, Blenkinsopp et al. (2019) defined healthcare whistleblowing as the raising of concerns about unsafe, unethical or poor-quality care to persons able to effect action. As noted by Lim et al. (2021), despite its important role in protecting patient safety, whistle-blowing is viewed as the exception rather than the norm in healthcare. Equally important, worried healthcare workers often remain quiet for numerous reasons such as the confidence that nothing will be done anyway, fright of associative retaliation such as not wanting to get a coworker into trouble and then being flagged as a snitch by other coworkers. Because beliefs like these can lead to a compromise of patient safety, it is vital to examine the positive and negative 
consequences that can be produced from whistle-blowing.

As an illustration, whistle-blowing has led to many useful conclusions such as increased accountability and transparency in different healthcare arenas. Additionally, it has also spurned the development of strategies to better detect existing systemic gaps and enforce enacted policies and legislations. Increased public and media interest is often a catalyst for these changes to safeguard patient safety.

In comparison, individuals have often experienced multiple negative consequences for their decision to whistle-blow such as being "blacklisted" as compared with whistle-blowers in other industries (Furlow, 2011). Furthermore, within the healthcare sector, even though the bulk of the whistle-blowing studies has been piloted among nurses, physicians and researchers, whistle-blowers seem to encounter related pessimistic outcomes on their careers, alliances, economics, psychological, and bodily well-being. This similarity infers those teachings and improvements from whistle-blowing in one healthcare field (e.g., nursing) might be conjectured to another (e.g., clinical research) (Lim et al., 2021).

The final analysis is that comprehending such outcomes would assist would-be whistle-blowers to better devise and accumulate the needed base and means for what lies ahead. Granted that and even more important, regardless of whether the individual is a healthcare worker, manager, or guideline creator, comprehending the complicated influence of whistle-blowing is key to confess how they can best support whistle-blowers to safeguard patient safety (Lim et al, 2021).

\subsection{Ethics and Whistleblowing}

Gardner (2007) concluded that a whistleblower is the type of individual that displays an ethical mind and that this type of ethical orientation begins at home where children absorb their parent's values (p. 53). Apple's CEO Tim Cook held a similar view when he explained what breeds ethical leadership and what it means to be an ethical leader in his view. Tim Cook stated that the compass of ethical leadership starts at home and is a byproduct of whom you surround yourself with in your business and personal affairs. He further argued that ethics in his view is leaving things better than how you've found them and all this is tied back to the values that you were exposed to from your home, friends, and those that have influenced you the most (Duke University, 2013).

Although this may be true, values can be explained in different manners. First, Velasquez (1999) defined values as those perspectives communicated as declarations expressing things or characteristics of things that have value. They specify what people believe is principle in ruling. Values may also be explained as the underlining set of beliefs and truths considered to be preferable by groups of individuals (Payne \& Landry, 2005). Values are acquired from one's belonging in a circle or culture. In particular, values are acquired from moral standards absorbed as a child from family, friends, church, and school. Hence, combined with attitudes, beliefs, and behaviors, values form a continuous spiral of community culture (Payne, 2003) See Figure 1.1 below. 


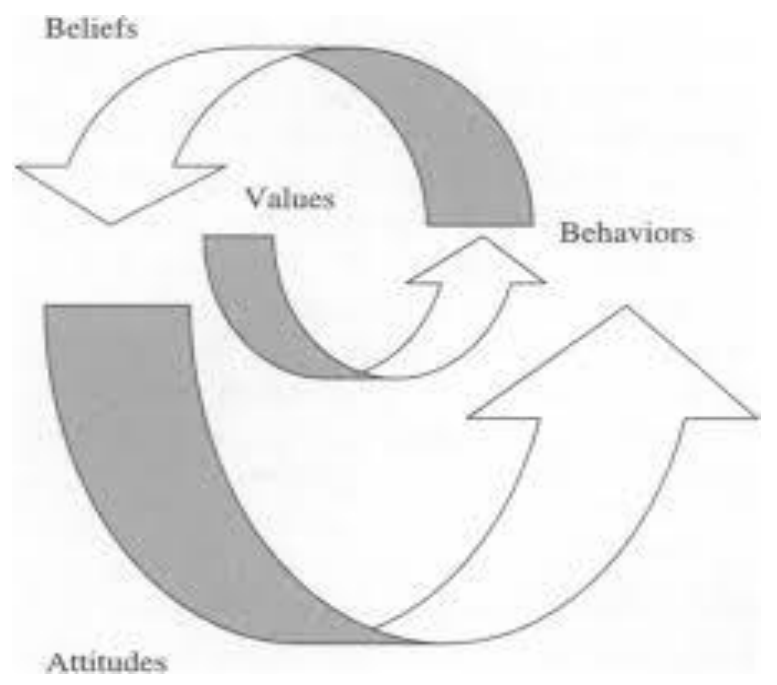

Figure 1.1. Spiral of Developing Culture (Payne, 2003)

Looking back at Gardner's conclusion about a whistleblower displaying an ethical mind, ethics can also be defined in different ways. For instance, ethics can be interpreted as the belief of what is right and fair conduct (Carroll, 1979). Moreover, ethics is also a synonym for principles in that it can be viewed as one's ability to choose between right or wrong, good or bad. "Ethics calls for the choices of free people who are enlightened and reasoned (Laudon, 1995, p. 5). Knowing this, Laudon (1995) concluded that four distinct schools of ethics thinking could be derived. See Figure 1.2 below.

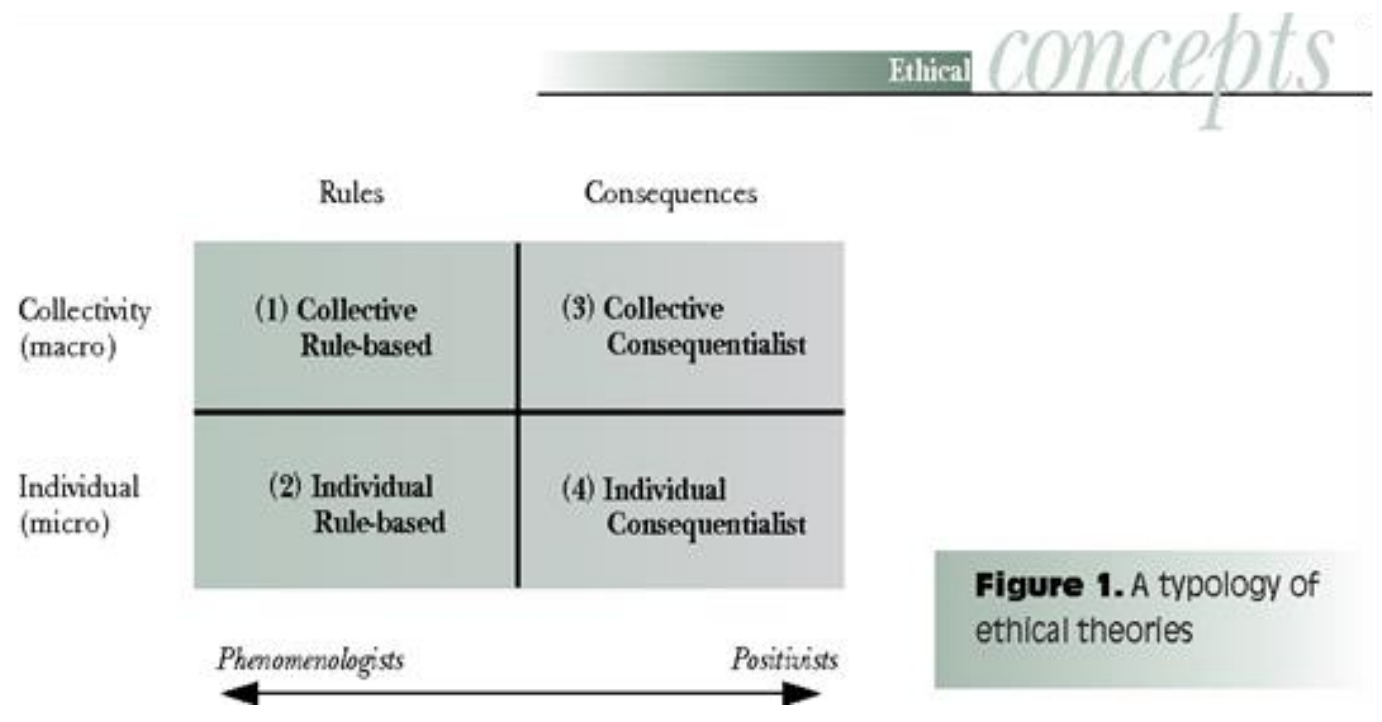

Figure 1.2. Four distinct schools of ethical thinking (Laudon, 1995. P.35)

Hence, building moral or ethical judgements suggests that the administrator is perturbed with the moral rightness or wrongness of the decision, rather than just the legality of the decision is the kind of conviction that a whistleblower takes when faced with an ethical decision (Payne \& Landry, 2005). 


\section{Macrothink \\ International Journal of Human Resource Studies \\ ISSN 2162-3058 \\ 2022, Vol. 12, No. 1}

\subsection{Whistleblowing Processes in Healthcare}

Mannion and Davies (2015) appraised whistleblowing a process that follows previous unceremonious attempts to discover wrongdoings and to probe whether what is happening in the organization is really wrong. Although this is true, to date, there is still not much research on how to effectively implement whistleblowing practices and processes in health care because whistleblowing has only recently become a mainstream issue in healthcare (Holt, 2015). Nevertheless, Pohjanoksa et al. (2019) depicted three different whistleblowing processes in healthcare that can be used to build future research around this topic. See Figures' $1.3,1.4$ and 1.5 below.

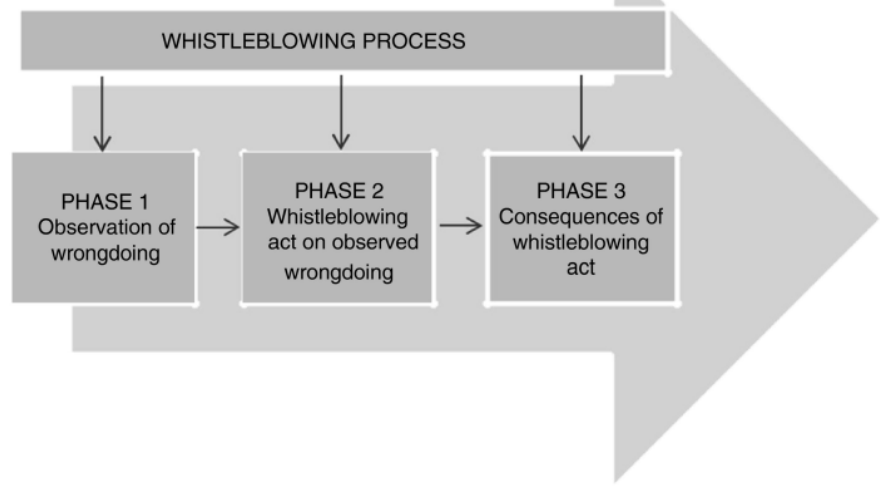

Figure 1.3. Whistleblowing process in healthcare (Pohjanoksa et al., 2019)

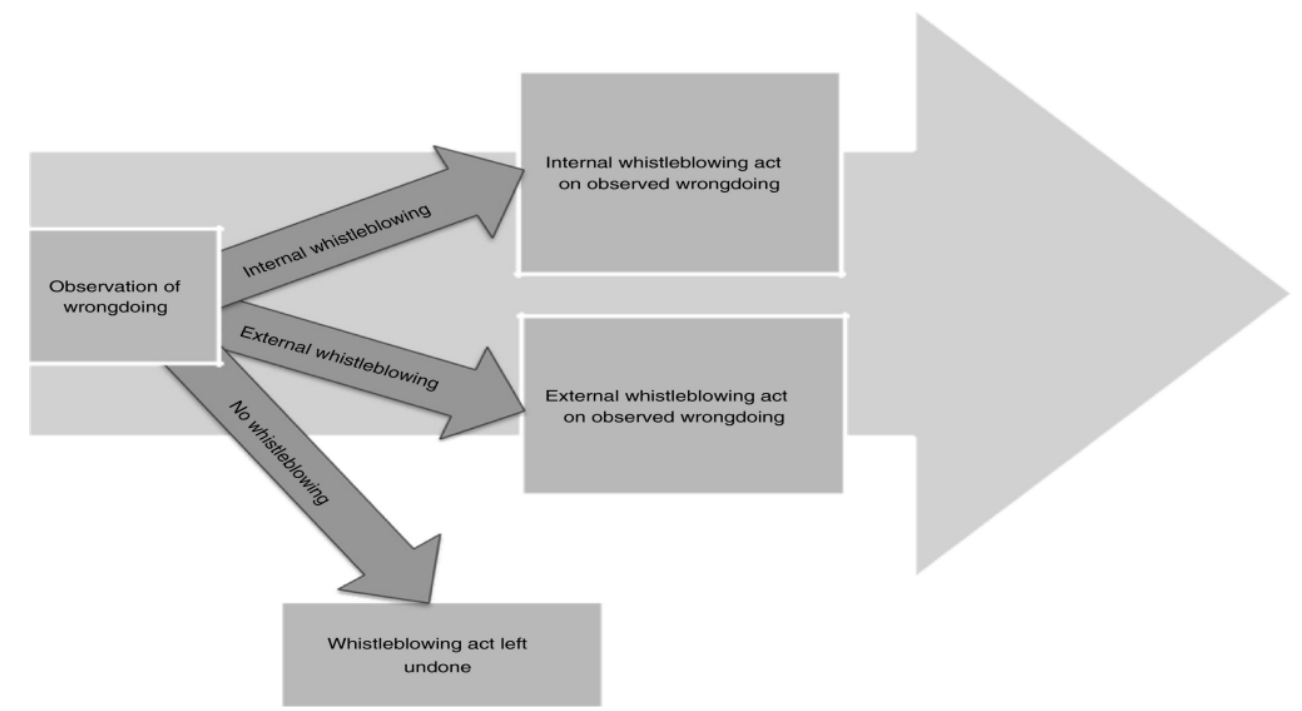

Figure 1.4. Whistleblowing process' paths from observation of wrongdoing to whistleblowing acts: Internal whistleblowing, External whistleblowing and No whistleblowing (Pohjanoksa et al., 2019) 


\section{Ml Macrothink \\ International Journal of Human Resource Studies \\ ISSN 2162-3058 2022, Vol. 12, No. 1}

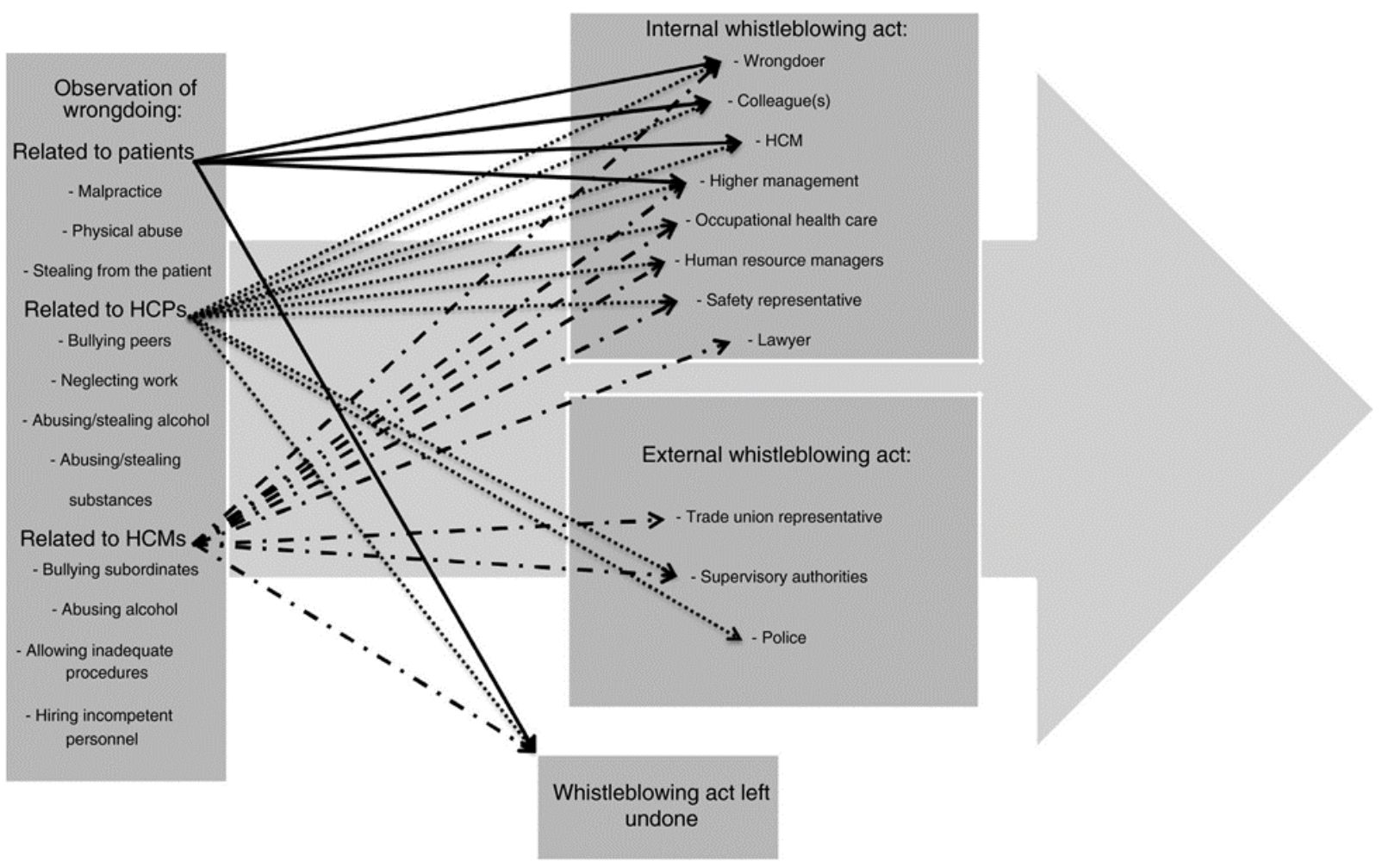

Figure 1.5. Whistleblowing process and paths from an observation of wrongdoing related to patients, healthcare professionals (HCP) and healthcare managers (HCM) to internal, external and whistleblowing act left undone (Pohjanoksa et al., 2019)

As noted by Pohjanoksa et al. (2019), the findings from the three processes above bolstered the position of the whistleblowing process in healthcare care by identifying two phases of the process, (1) an observation of wrongdoing and (2) a whistleblowing act regarding it more visible and identifying the paths combining these two phases. Also, three themes of observed wrongdoing were identified: wrongdoing related to (a) patients, (b) HCPs, and (c) HCMs and three main paths between them and whistleblowing acts were identified: internal, external, and no whistleblowing. Nevertheless, the findings ultimately reveal that an observation of wrongdoing is always the starting point of the path, but the paths and whistleblowing acts vary (p. 1514).

\subsection{Levels of Whistleblowing in Healthcare}

As noted by Moore and McAuliffe (2010), healthcare professionals have a responsibility to maintain standards of care and this responsibility includes taking action to report poor care (p. 166). Thus, when it comes to healthcare, there are three different levels to whistleblowing that could be used to report patient safety - societal, organizational, and individual. See Figure 1.6 below. 


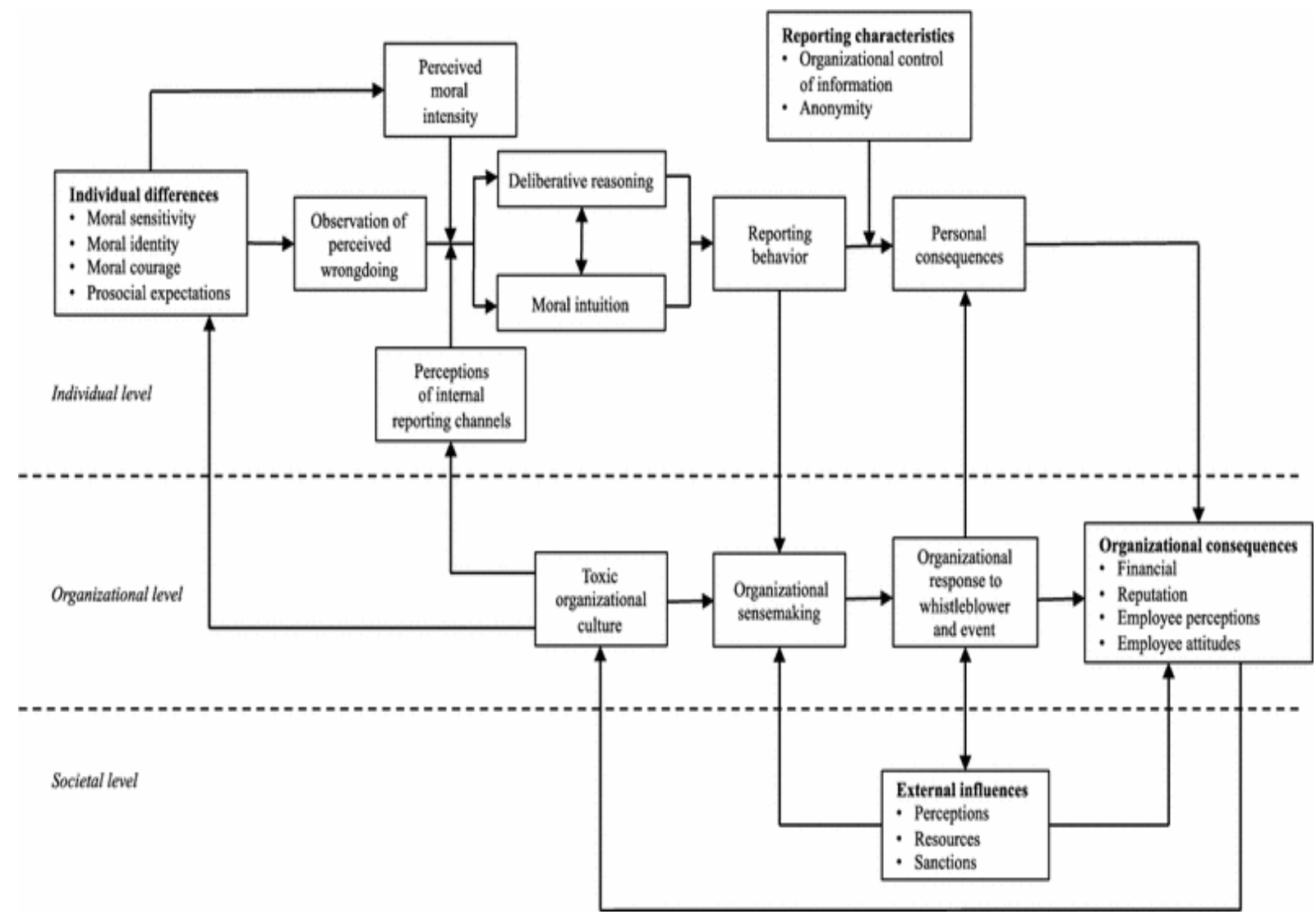

Figure 1.6. Three levels of whistleblowing (Watts \& Buckley, 2017)

Focusing on the individual level of whistleblowing reporting as an example, Watts and Buckley (2017) concluded that one of the individual differences that an individual should have when it comes to whistleblowing is to have morale courage. Watts and Buckley noted that individuals that are high in moral courage are more likely to recognize and ultimately report perceived organizational wrongdoing (p. 674). Durante and Gökçe (2017) held a similar view in stating that moral courage is one of the most important factors to understanding one's propensity to blow the whistle (p. 1047).

\subsection{Organizational Factors That Can Inhibit and Foster Whistleblowing in Healthcare}

Internal Reporting refers to any time that a member of an organization (or a former member) tells someone else about an illegal or immoral practice, if the telling is done in the hope that someone will do something to change the practice. According to Vadera et al. (2009), Internal reporting is also known as internal whistle blowing. When organizations punish or discourage internal reporting, bad practices typically get worse, until someone-often motivated by conscience - feels they must notify the press, or a government agency. On the contrary, when organizations reward and promote internal reporting, lessons are learned and ultimately patient safety measures and policies are improved. By this means, Vadera et al. (2009) noted several organizational factors that can inhibit internal reporting towards whistleblowing and those that can promote internal reporting towards whistleblowing.

$>$ Organizational factors that inhibit whistleblowing process 


\section{Macrothink \\ International Journal of Human Resource Studies

- Unavailable resources (e.g., hotline)

- Hostile or unethical organizational culture

- Toxic leadership

- Lack of organizational justice

Organizational factors that foster whistleblowing process

- Implement structures and policies that visibly protect and incentivize internal reporting

- Make ethics part of the core organizational values

- Leaders must be active listeners and role models of integrity (Vadera et al., 2009)

The underlining theme that drives Vadera's organizational factors towards whistleblowing is leadership. Longenecker et al. (2014) cited that ineffective leadership and lack of trust in upper management is a barrier towards fostering an organizational culture that embraces successful change and improvement on an ongoing basis (p. 151). Accordingly, Shafritz et al. (2016) concluded that leadership can be viewed as an action in which one has the ability to influence others towards achieving a set of objectives that have been communicated.

To this end, Tan and Jeffrey (2015) had a similar view in stating that organizational factors such as staff engagement and commitment of the department heads are perceived to be significant in promoting best practices for patient safety and it all starts with leadership. Finally, when the focus is on organizational factors as it relates to leadership, Longenecker et al. (2014) concluded that leaders must demonstrate a high level of competence and character, and they must lead by example (p. 152).

\subsection{Building and Sustaining an Ethical Culture Towards Whistleblowing in Healthcare}

Knowing the importance of building an ethical culture, Gallagher (2013) suggested to have the following steps in place as a guide to help build and sustain an ethical culture where whistleblowing is viewed as a morale right - (1) Recognize that unethical choices never start large; (2) Understand the three components of human behavior that lead to ethical lapses (i.e., need, opportunity and rationalization); (3) Be clear about what ethical behavior looks like; (4) Train, Train, Train; (5) Encourage accountability; and (6) When in Doubt, Do the Right Thing (p. 21). To illustrate the six steps, See figure 1.7 below. 


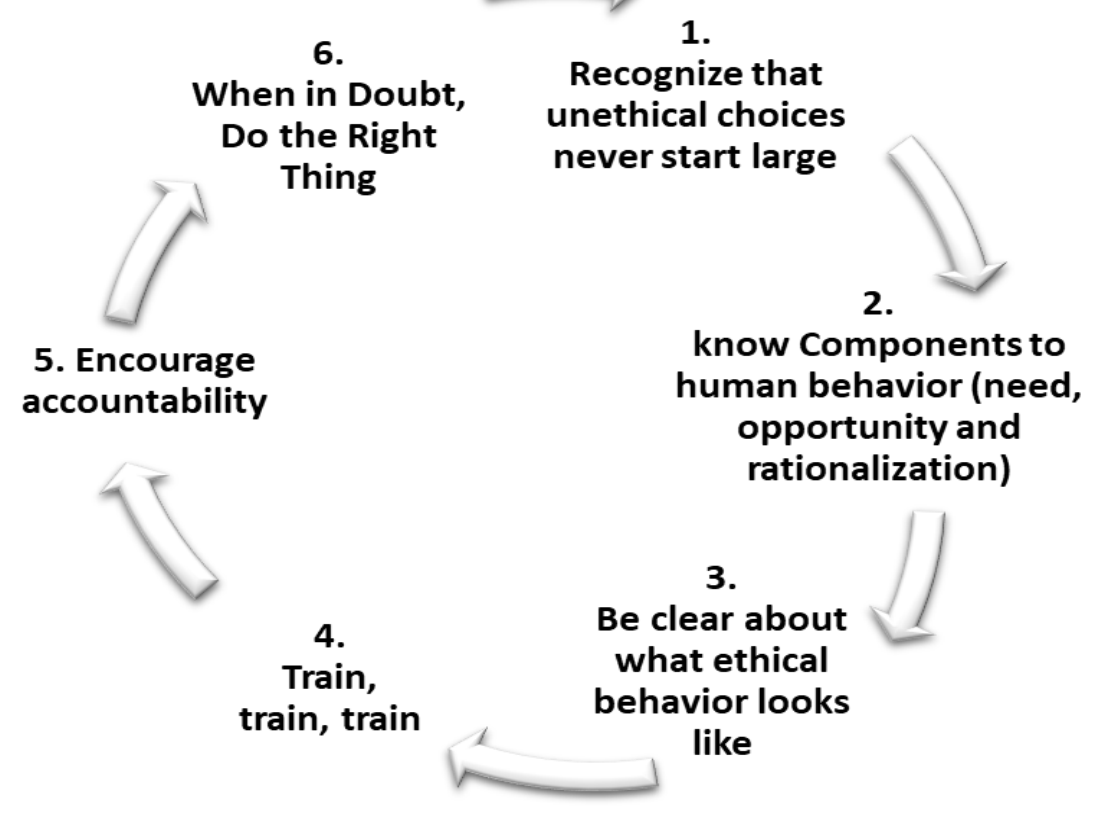

Figure 1.7. Steps to promote a culture where whistleblowing is viewed as a morale right (Gallagher, 2013)

\section{Methodology and Data Collection}

\subsection{Research Method and Design}

The purpose of this literature review was to examine the role of organizational culture and change in healthcare, the link between ethics and whistleblowing, and the processes and levels of whistleblowing within healthcare. Additionally, the goal of this research was to explore the organizational factors that both inhibit and foster whistleblowing within healthcare. In terms of design, an integrative literature review was chosen for various reasons. The first reason was because Simon and Goes (2013) stated that performing an extensive literature review can be noted as the underlining objective when performing a study (p. 277).

The second reason why a literature review design was best suited for this research was that it offered the opportunity to use a blend of critical essays that examined and unified the most relevant and current published knowledge on the topic under investigation. The final reason why a literature review design was deemed most appropriate for this research was that it presented an avenue to systematically and broadly collect, analyze, and integrate experimental and nonexperimental research into meaningful wholes to understand a phenomenon The above reasons were well aligned with this study selected because the goal was to understand a broad range of organizational factors that can be used as a foundation to help organizations create an ethical culture that views whistleblowing as a positive consequence.

\subsection{Data Collection}

The ProQuest database and GOOGLE SCHOLAR was the primary source and EBSCO was the secondary database used in this literature review. The search keywords used were Whistleblower, Organizational Culture, Patient Safety, Healthcare Whistleblowing, and 


\section{$\Lambda$ Macrothink}

International Journal of Human Resource Studies

ISSN 2162-3058

2022, Vol. 12, No. 1

Ethics. Articles researched for this literature review provided an overview of whistleblowing that focused on healthcare, ethics, values, patient safety, and attitudes for the healthcare worker. After researching articles on whistleblowing studies, the researcher continued the review with articles about the healthcare industry, organizational culture, the positive and negative consequences of whistleblowing, and the impact that whistleblowing can have on the patient's health.

The research documents included in this study were published and compiled by various sources. Lastly, this literature review consisted of both U.S. and international journals on management, organizational behavior, organizational culture, ethics, patient safety, and leadership. Specific journals included - Industrial and Commercial Training, Journal of health organization and management, Academy of Management Review, Leadership Excellence Essentials, International Journal of Health Policy and Management, The Ethics of Information Technology and Business, Journal of advanced nursing, International Journal of Caring Sciences, Harvard Business Review, Journal of Healthcare Management, Journal of Business Ethics, Australian Nursing and Midwifery Journal, Business Ethics Quarterly, TQM Journal, Employee Responsibilities and Rights Journal, Journal of patient safety, Nursing Management (Harrow).

\section{Instrumentation and Setting}

As for instrumentation, the researcher used secondary data as its main source of instrumentation. However, as Creswell (2014) noted, in research, the researcher can also be included as an instrument because the researcher collects data themselves through examining documents, or observing behavior. Therefore, the researcher was the second source of instrumentation used. Furthermore, because research setting is an important component of research design/methodology, the researcher focused on exploring themes and patterns around organizational culture and change in healthcare, the link between ethics and whistleblowing, and the processes and levels of whistleblowing within healthcare as its research setting. This is in contrast to similar authors who focused on questions as its source for results when performing a literature review for their setting.

\section{Study Taxonomy}

As defined by Bradley et al. (2007), taxonomy is a system for classifying multifaceted, complex phenomena according to common conceptual domains and dimensions. Bradley further stated that the purpose of employing taxonomy is to increase clarity in defining and comparing complex phenomena (p. 1761). As a result, because whistle-blowing is viewed as the exception rather than the norm in healthcare, the researcher used different lenses to look at the complicated problems and social issues within this phenomenon. With that said, the following domains for this study was developed.

\subsection{Leadership}

Longenecker et al. (2014) cited that ineffective leadership and lack of trust in upper management is a barrier towards fostering an organizational culture that embraces successful change and improvement on an ongoing basis (p. 151). Accordingly, Shafritz et al. (2016) concluded that leadership can be viewed as an action in which one has the ability to influence 
others towards achieving a set of objectives that have been communicated.

To this end, Tan and Jeffrey (2015) had a similar view in stating that organizational factors such as staff engagement and commitment of the department heads are perceived to be significant in promoting best practices for patient safety and it all starts with leadership. Finally, when the focus is on organizational factors as it relates to leadership, Longenecker et al. (2014) concluded that leaders must demonstrate a high level of competence and character, and they must lead by example (p. 152).

\subsection{Individual Level of Whistleblowing in Healthcare}

Watts and Buckley noted that individuals that are high in moral courage are more likely to recognize and ultimately report perceived organizational wrongdoing (p. 674). Durante and Gökçe (2017) held a similar view in stating that moral courage is one of the most important factors to understanding one's propensity to blow the whistle (p. 1047).

\section{Limitations of Research}

Although every effort was made to capture all relevant papers and documents in the various reviews using comprehensive search strategies, some may have been missed as this area is challenging. Also, although this is a phenomenon in the form of real life, this research did not consist of using human subjects to conduct interviews or ask questions, so findings may not be as robust towards exploring and understanding the behavioral factors of individuals or groups within an organization. Lastly, the income of countries or geographical regions wherein were not used as a factor towards determining how well whistleblowing is accepted as a practice in healthcare for patient safety.

\section{Conclusion}

Patient safety has progressed over the last decade from being a relatively insignificant issue to a position high on the agenda for healthcare professionals, managers and policy makers (Skagerström et al., 2017). What's more, the importance of building a trustful relationship between the healthcare professional and the patient to make patients feel comfortable should be the ultimate goal of the healthcare professional. Hence, with that said, As quoted by Gardner (2007), "If you are not prepared to resign, or be fired for what you believe in, then you are not a worker, let alone a professional, you are a slave (Gardner, 2007).

Gardner further stated that, in the end, you need to decide which side you are on. There are many ways in which the world can either spiral up toward both health and a decent life for all or down into poverty, disease, ecological disaster -even nuclear warfare. If you are in a position to help tip the balance, you owe it to yourself, to your progeny, to your employees, to your community, and to the planet to do the right thing" (p. 56). Hamilton (2005) came to a similar conclusion in stating that when it comes to patients, one should want to do what is right even though there are laws in place to protect them.

For this reason, DeGeorge (2003) concluded that we should not equate laws with ethics because of the fact that even though a law is considered to be permitted, this does not mean it is ethical, which was the case with apartheid laws in South Africa (p. 17). To this end, as 
quoted by Dalai Lama - "No one should suppose it could ever be possible to devise a set of rules or laws to provide us with the answer to every ethical dilemma...such a formulaic approach could never hope to capture the richness and diversity of human experience. It would also give grounds for arguing that we are responsible only to the letter of those laws, rather than our actions" (The Dalai Lama, 1999, p. 27). The final analysis is that in the healthcare industry, whistleblowing should be viewed as an ethical decision to help provide quality care, which in essence will improve the patient experience and ultimately keep patients safe (Faunce, 2004).

\section{Recommendations for Future Research}

Future research is needed around investigating whistleblowing as an unfolding, situated and interactional process and not just a one-off act by an identifiable whistleblower. Specifically, we need more evidence and insights into the tendency for senior leadership not to hear, accept or act on concerns about the care raised by healthcare workers. Secondly, there is a need to consolidate and build on existing knowledge and to better situate studies within complex local, national, and international policy contexts and culturally diverse workforces. Thirdly, more studies of whistleblowing in healthcare within Lower- and Middle-Income Countries would address a significant gap from this literature review and provide better understanding and solutions to meet the demands therein.

Lastly, future research could focus on gaining a deeper understanding of whistleblowing and the whistleblowing process, using in-depth interviews with healthcare workers with experiences of performing whistleblowing acts. These experiences could also be explored using creative research methods such as writing stories, using diaries, or writing lyrics or poems. Research could also focus on confirming the whistleblowing process, paths in the process, and potential patterns in those paths. Moreover, research could focus on individual characteristics, such as the moral courage of healthcare workers who perform the whistleblowing act or leave it undone. These individual characteristics could be investigated using written or video vignettes about hypothetical wrongdoing.

\section{References}

Appelbaum, S. H., Degbe, M. C., MacDonald, O., \& Nguyen-Quang, T. (2015). Organizational outcomes of leadership style and resistance to change (Part One). Industrial and Commercial Training, $47(2)$, 73-80. https://www.emerald.com/insight/content/doi/10.1108/ICT-07-2013-0044/full/html

Berry, B. (2004). Organizational culture: a framework and strategies for facilitating employee whistleblowing. Employee Responsibilities and Rights Journal, 16(1), 1-11.

Blenkinsopp, J., Snowden, N., Manion, R., Powell, M., Davies, H. T. O., Millar, R., \& McHale, J. (2019). Whistleblowing over patient safety and care quality: a review of the literature. Journal of health organization and management. https://doi.org/10.1108/JHOM-12-2018-0363

Blesch, G. (2010). Lone Star State showdown. Modern Healthcare, 40(5), 12. 


\section{MInstitute Macrothink $_{\text {Int }}$}

International Journal of Human Resource Studies

ISSN 2162-3058

Bowman, J. S. (1980). Whistle-blowing in the public service: an overview of the issues. Review of Public Personnel Administration, 1(1), 15-27. http://citeseerx.ist.psu.edu/viewdoc/download?doi=10.1.1.1022.2076\&rep=rep1\&type=pdf

Bradley, E. H., Curry, L. A., \& Devers, K. J. (2007). Qualitative data analysis for health services research: developing taxonomy, themes, and theory. Health services research, 42(4), 1758-1772. Retrieved from https://www.ncbi.nlm.nih.gov/pmc/articles/PMC1955280/

Carroll, A. B. (1979). A three-dimensional conceptual model of corporate performance. Academy of Management Review 4(4), 497-505.

Ciasullo, M. V., Cosimato, S., \& Palumbo, S. (2017). Improving health care quality: the implementation of whistleblowing. TQM Journal, 29(1), 167-183. https://doi.org/10.1108/TQM-06-2016-0051

Creswell, J. W. (2014). Research design: Qualitative, quantitative and mixed methods Approaches (4th ed). Thousand Oaks, CA: Sage Publications

Dalai Lama. (1999). Ethics for the new millennium. New York: Riverhead Books.

DeGeorge, R. T. (2003). The Ethics of Information Technology and Business. Malden, MA: Blackwell Publishing Ltd.

Duke University. (2013). Apple CEO Tim Cook on ethical leadership.

Durante, R., \& Gökçe, A. T. (2017). Organizational culture and ethics: The influence organizational and personal values have on perceptions of misconduct and the factors of whistleblowing. Encyclopedia of Strategic Leadership and Management, 1047-1048

Evans, J. M., Baker, G. R., Berta, W., \& Barnsley, J. (2015). Culture and cognition in health systems change. Journal of Health Organization and Management, 29(7), 874-892. https://doi.org/10.1108/JHOM-06-2014-0101

Faunce, T. (2004). Developing and teaching the virtue-ethics foundations of healthcare whistle blowing. Monash Bioethics Review, 23(4), 41-55. Retrieved from https://law.anu.edu.au/sites/all/files/users/u9705219/236_oct_mbr_final_short.pdf

Furlow, B. (2011). US physician whistleblowers face intimidation and retaliation. The Lancet Oncology, 12(8), 727.

Gallagher, C. (2013). Whistleblowing - How to build a culture of ethics. Leadership Excellence Essentials, 30(11), 21.

Gardner, H. (2007). The ethical mind. A conversation with psychologist Howard Gardner. Harvard Business Review, 85(3), 51-56.

Hamilton, A. (2005). The development and operation of IRB's: Medical regulation and social science. Journal of Applied Communication Research, 33(3), 189-203. https://www.tandfonline.com/doi/abs/10.1080/00909880500149353 
Holt, K. (2015). Whistleblowing in the NHS. British Medical Journal, 350, 1-2.

Johnstone, M. J. (2009). Moral excellence and patient safety. Australian Nursing and Midwifery Journal, 16(8), 25. Retrieved from https://www.proquest.com/docview/236590217?pq-origsite=gscholar \&fromopenview=true

Laudon, K. C. (1995). Ethical concepts and information technology. Communications of the ACM 38(12), 33-39. Retrieved from https://web.archive.org/web/20180826220337id_/http://dave-reed.com:80/csc599.F17/laudon .pdf

Lim, C. R., Zhang, M. W., Hussain, S. F., \& Ho, R. C. (2021). The consequences of whistle-blowing: an integrative review. Journal of patient safety, 17(6), e497-e502. Retrieved from

https://journals.lww.com/journalpatientsafety/Fulltext/2021/09000/The_Consequences_of_W histle_blowing_An.14.aspx?casa_token=d4ZUcI_7yIcAAAAA:R9S5Yg87pq8pdUgXO9X Xlj7C3ta4iXtlfpAO15SFIuPF8R_8p5iLUlsNFKhe2SwJrAjKCFIJUWfOTkuC_bK3fH4

Longenecker, C. O., Longenecker, P. D., \& Gering, J. T. (2014). Why hospital improvement efforts fail: A view from the front line. Journal of Healthcare Management, 59(2), 147-157. Retrieved

from https://journals.lww.com/jhmonline/Fulltext/2014/03000/Why_Hospital_Improvement_Effort s_Fail_A_View_From.10.aspx?casa_token=5-aIAinzH9gAAAAA:48TJMgjnWypD8RovzI2 dzy7g89FfN3AkH8M97kJy5pjKA7AtO182VST8Sc-CBN84s9TjcXoS7AfxlyJrTOPvULU

MacDougall, D. R. (2016). Whistleblowing: don't encourage it, prevent it. International Journal of Health Policy and Management, 5(3), 189-191. Retrieved from https://www.ncbi.nlm.nih.gov/pmc/articles/PMC4770925/

Mannion, R., \& Davies, H. T. (2015). Cultures of silence and cultures of voice: the role of whistleblowing in healthcare organizations. International Journal of Health Policy and Management, 4(8), 503-505. https://doi: 10.15171/ijhpm.2015.120

Moore, L., \& McAuliffe, E. (2010). Is inadequate response to whistleblowing perpetuating a culture of silence in hospitals? Emerald Group Publishing Limited, 15(3), 166-178.

Myers, A. (2008). Whisteblowing saves lives. Nursing Management (Harrow), 15(3), 3-4.

Payne, D. (2003). Engineering ethics and business ethics: Commonalities for a comprehensive code of ethics, IEEE Annual Conference in press.

Payne, D., \& Landry, B. J. (2005). Similarities in business and IT professional ethics: The need for and development of a comprehensive code of ethics. Journal of Business Ethics, 62(1), 73-85. https://doi.org/10.1007/s10551-005-3439-3

Pohjanoksa, J., Stolt, M., Suhonen, R., \& Leino-Kilpi, H. (2019). Wrongdoing and whistleblowing in health care. Journal of advanced nursing, 75(7), 1504-1517

Shafritz, J. M., Ott, J. S., \& Jang, Y. S. (2016). Classics of organization theory (8th ed.). Boston, 
MA: Cengage Learning.

Simon, M., \& Goes, J. (2013). Dissertation and Scholarly Research: A Practical Guide to Start and Complete Your Dissertation, Thesis, or Formal Research Project. Dissertation Success (13th ed).

Skagerström, J., Ericsson, C., Nilsen, P., Ekstedt, M., \& Schildmeijer, K. (2017). Patient involvement for improved patient safety: a qualitative study of nurses' perceptions and $\begin{array}{llll}\text { experiences. } & \text { Nursing } & \text { open, } & \text { 230-239. }\end{array}$ https://onlinelibrary.wiley.com/doi/full/10.1002/nop2.89

Suwaryo, J., Daryanto, H. K., \& Maulana, A. (2016). Organizational Culture Change and its Effect on Change Readiness through Organizational Commitment. Bisnis \& Birokrasi: Jurnal Ilmu Administrasi dan Organisasi 22(1), 68-78. Retrieved from https://scholarhub.ui.ac.id/cgi/viewcontent.cgi?article=1086\&context=jbb

Tan Jr, A. K., \& Jeffrey Olivo, B. S. (2015). Assessing healthcare associated infections and hand hygiene perceptions amongst healthcare professionals. International Journal of Caring Sciences, $\quad 8(1), \quad 108-114 . \quad$ Retrieved from https://www.researchgate.net/profile/Amil-Kusain-Jr-Tan-2/publication/270957755_Assessin g_Healthcare_Associated_Infections_and_Hand_Hygiene_Perceptions_amongst_Healthcare_ Professionals/links/54ba6d460cf24e50e9401d4d/Assessing-Healthcare-Associated-Infections -and-Hand-Hygiene-Perceptions-amongst-Healthcare-Professionals.pdf

Taylor, V. (2010). Another hospital saga: the chronicles of Professor Kossmann and Bayside Health. J Law Med., 18, 76-102

Ting, M. M. (2008). "Whistleblowing”. American Political Science Review, 102(2), 249-267. Retrieved from https://escholarship.org/content/qt3nb657ts/qt3nb657ts.pdf

Vadera, A. K., Aguilera, R. V., \& Caza, B. B. (2009). Making sense of whistle-blowing's antecedents: Learning from research on identity and ethics programs. Business Ethics Quarterly, 19(4), 553-586. https://doi.org/10.5840/beq200919432

Velasquez, M. G. (1999). Business Ethics: Cases and Concepts. Englewood Cliffs: Prentice Hall.

Watts, L. L., \& Buckley, M. R. (2017). A dual-processing model of moral whistleblowing in organizations. Journal of Business Ethics, 146(3), 669-683. https://link.springer.com/article/10.1007/s10551-015-2913-9

\section{Copyright Disclaimer}

Copyright for this article is retained by the author(s), with first publication rights granted to the journal.

This is an open-access article distributed under the terms and conditions of the Creative Commons Attribution license (http://creativecommons.org/licenses/by/4.0/). 